\title{
Coulisses
}

Revue de théâtre

14 | Printemps 1996

Varia

\section{Variations autour de Une Demande en Mariage de Tchekhov par le TUFC de Montbéliard}

\section{Marcel Kodjovi Djondo}

\section{(2) OpenEdition}

1 Journals

Édition électronique

URL : http://journals.openedition.org/coulisses/4535

DOI : $10.4000 /$ coulisses.4535

ISSN : 2546-9460

Éditeur

Presses universitaires de Franche-Comté

\section{Édition imprimée}

Date de publication : 1 mai 1996

Pagination : 32

ISSN : 1150-594X

\section{Référence électronique}

Marcel Kodjovi Djondo, "Variations autour de Une Demande en Mariage de Tchekhov par le TUFC de Montbéliard », Coulisses [En ligne], 14 | Printemps 1996, mis en ligne le 20 mars 2019, consulté le 28 octobre 2019. URL : http://journals.openedition.org/coulisses/4535; DOI : 10.4000/coulisses.4535

Ce document a été généré automatiquement le 28 octobre 2019.

Coulisses 


\title{
Variations autour de Une Demande en Mariage de Tchekhov par le TUFC de Montbéliard
}

\author{
Marcel Kodjovi Djondo
}

1 Pourquoi Une Demande en Mariage? La question ne s'est pas vraiment posée dans le groupe et le choix s'est fait de façon spontanée après quelques lectures. Le TU de Montbéliard ayant pour vocation le théatre d'intervention, donc beaucoup d'improvisation, nous nous sommes donné comme projet de construire ces improvisations autour du thème du mariage par intérêt. C'est celui qui, au travers de nos premières lectures, semblait revenir le plus souvent. D'autre part, nous ne voulions pas monter une pièce entière de Tchékhov. C'est dans cette optique que le travail a été attaqué.

2 Personnellement, j'étais moi aussi dans les premiers préparatifs de mon mariage (pour de vrai). Hasard ou pas, ce travail a été pour moi une manière de préparer cet événement et de faire en sorte que le théâtre permette de combler certains vides de la réalité.

Quels processus pour quelle création? Peut-on parler de création? Il s'agirait plutôt d'une « récréation » et d'une "répétition ». Récréation parce que c'est un moment qui a permis aux étudiants de revêtir leurs costumes de gendarme et de voleur tout comme dans une cour de " récré ", pour jouer avec toute la sincérité et tout le plaisir.

«Ré-création » et "répétition » car demander une fille en mariage est un geste que nous avons malheureusement perdu, un moment théâtral intense que nous avions dans nos cultures que ce soient celles du Nord, du Sud, de l'Est ou de l'Ouest.

3 Tchékhov, en peignant la scène de cette demande en mariage, nous donne le matériau auquel nous devons insuffler une vie : dans cette « ré-création » nous avons donc pris le parti de faire le même rituel que nos ancêtres, répéter cette scène pour la perpétuer à travers des générations dans une sorte de protocole ludique et imaginaire.

Pour aboutir à ces variations autour de Une Demande en Mariage le processus du travail a été le suivant : lecture - discussion - choix - improvisation - écriture. 
4 Les scènes se sont mises en place de façon rapide. Nous avons pris appui sur les coutumes de différents pays. C'est ainsi qu'une première improvisation est partie d'une pratique du sud-Togo et une deuxième de l'ex-Yougoslavie.

5 Ces deux improvisations ont été tellement fortes que nous avons décidé de les garder et de les approfondir. À l'arrivée il ne s'agira plus du sud-Togo ni de l'ex-Yougoslavie mais de Mogadougou et de Yakata. Et dans ces produits de l'imagination il devenait difficile de dire qui était qui et de s'y retrouver, pour le spectateur. Pendant les improvisations, nous avons été surpris par certaines similitudes de situations, de personnages et d'intentions avec le texte. Nous avons donc gardé nos personnages et nous avons fait un collage de quelques dialogues de Tchékhov, ce que nous avons d'ailleurs signalé aux spectateurs pendant le spectacle!

6 À l'arrivée...

... ce sont des étudiants qui savourent leur plaisir de jouer sur scène et devant un public, c'est un moment de spectacle gai et très enlevé et... un animateur-metteur en scène qui avait fait sa demande en mariage (pour de vrai !)

P.S. : Mon mariage - le vrai ! - est prévu pour le 25 mai 1996 dans les rues de Montbéliard.

Faire part de mariage de M. Djondo et A.M. Oberle

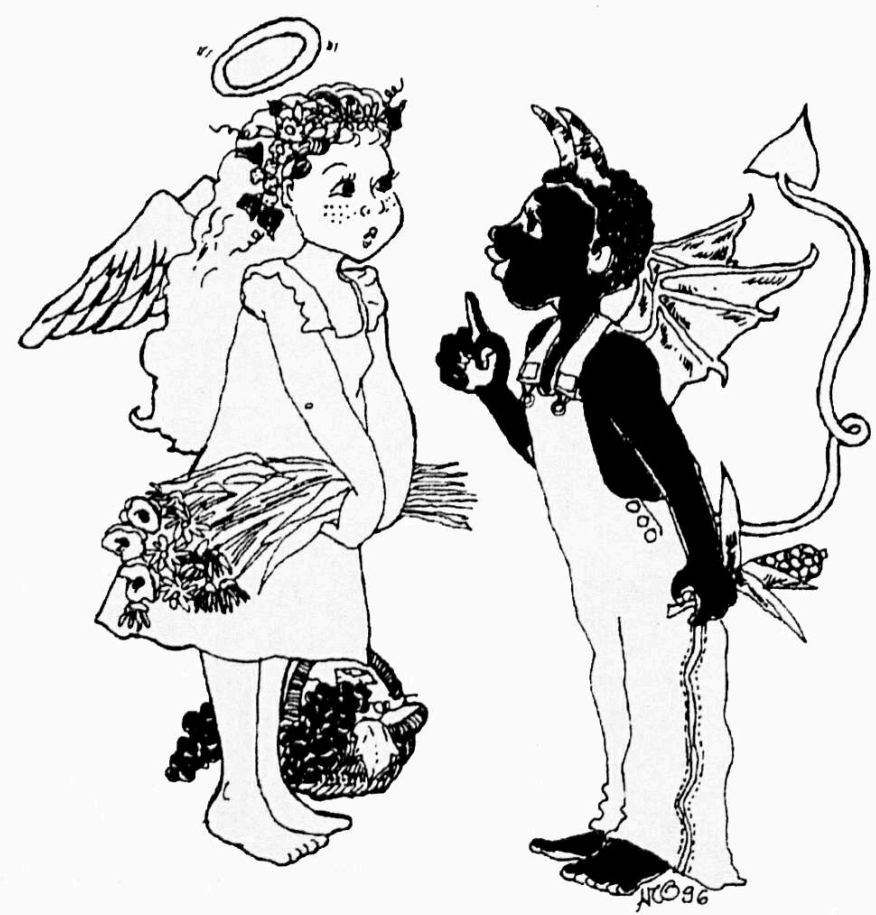

